\title{
Chemical Burn of Eye
}

National Cancer Institute

\section{Source}

National Cancer Institute. Chemical Burn of Eye. NCI Thesaurus. Code C118709.

Injury to the eye secondary to a chemical substance. 